\title{
What have the changes made to primary and secondary assessment frameworks since 2014 done to the 'London effect' in school performance?
}

\author{
Sean Hayes* - London Borough of Hounslow and University of Oxford, UK \\ Michael Jopling - University of Wolverhampton, UK \\ Ruki Gul - London Borough of Hounslow, London, UK
}

\begin{abstract}
This article examines whether the so-called 'London effect', in which London's schools improved rapidly and outperformed the rest of England on key performance measures between 2003 and 2013, has persisted through the high levels of change that have continued to characterize the school system in England since 2013. Using detailed analysis of educational attainment data, its primary focus is on determining whether the introduction in 2014 of significant changes to the primary curriculum and the national assessment frameworks in both primary and secondary phases affected the performance of London's schools in 2016, when the first examinations were taken under the new assessment systems.
\end{abstract}

Keywords: London; schools; assessment; accountability; effectiveness

\section{Introduction: The 'London effect' to 2013}

Although it was identified earlier, interest in a so-called 'London effect' in schools appears to have intensified from 2013 (Cook, 2013; Burgess, 2014; Mujtaba, 2016). The effect relates to the rapid improvements made by London's schools over several years on standard attainment measures, with primary and secondary schools consistently outperforming the rest of the country in examinations taken by pupils aged 10 to 11 (Key Stage 2) and 15 to 16 (Key Stage 4), respectively. Improvements in many London boroughs were remarkable, with London first outperforming national averages at Key Stage 2 in 2009 and at Key Stage 4 in 2004. This article explores whether the shift in educational outcomes in London observed between 2003 and 2013 in a series of research studies was sustained in 2016. We focused on 2016 because it was the first year in which examination outcomes reflected changes made to both primary and secondary assessment frameworks.

Although there is some consensus about the existence of the London effect, there is doubt about its exact nature and little agreement about its potential causes. National education policy in the decade from 2001 to 2010 had as much of an impact on London as anywhere, albeit perhaps more positively than in other regions of England. A number of structural changes and school improvement initiatives were associated with the improvements, not least the London Challenge and the City Challenge programme, which expanded the 2003-8 London Challenge to include Manchester and the Black Country and which ended in 2011. However, as Hayes and Cassen 
(2014) argue, there are many potential explanations for the London effect, not least the role played by local authorities (LAs). Even as their power and funding have been significantly reduced since the publication of the coalition government's White Paper, The Importance of Teaching (DfE, 2010): 'many London schools themselves and local authorities played crucial roles in securing the rapid improvement in outcomes over the life of the London Challenge and beyond' (Hayes and Cassen, 2014: 1). The attribution of the London effect to the London Challenge has been explored in a number of research studies. Hutchings et al. (2012) evaluated the City Challenge programme and associated it with gains in attainment, a reduction in the number of schools below the floor target and in London with a narrowing of the attainment gap between pupils eligible for free school meals (FSM) and those not eligible. They also found that schoolto-school collaboration played a key role, alongside school leadership and a data-rich approach to the Challenge's interventions, which represented 'a highly supportive and encouraging programme in which headteachers and teachers came to feel more valued, more confident and more effective' (Hutchings et al., 2012: 58).

A number of studies of London's schools followed. Kidson and Norris (2014: 2) reflected elements of Hutchings et al.'s (2012) findings, identifying 'successfully combined experimentation on the ground, rapid feedback and learning by advisers and officials, with strong project management across different strands of the policy' as key to the London Challenge's success in improving schools' Ofsted ratings and outcomes by 2010, particularly at Key Stage 4. In a study focused specifically on Tower Hamlets, Woods et al. (2013) found similar factors to be important in the transformation of education in the borough, alongside community development and a coherent, area-wide approach to improvement. Baars et al. (2014) found that in 2013 London's secondary schools outperformed all other regions, with 64.4 per cent of students achieving the then floor target of five or more GCSEs at $A^{*}-C$ including English and mathematics, compared to the national average of 60.2 per cent. They stated that London schools had consistently achieved better results, and improved at a faster rate, than the rest of the country combined since 2003-4, and also suggested that the achievement gap between FSM and non-FSM students was narrower than in other regions. The qualitative research they undertook associated these improvements with a number of 'enabling factors' which included effective leadership, finance, teacher recruitment, school buildings and four school improvement interventions (London Challenge, Teach First, the academies programme and local authority support).

Focusing on disadvantaged students and data between 2002 and 2012, Greaves et al. (2014) found that the proportion of students in Inner London achieving the floor target was lower than any other region in 2002, but second only to Outer London by 2012. They also suggested that the achievement gap between rich and poor was narrower in London than in the rest of the country, primarily because children from deprived backgrounds performed better. Most importantly, and reflecting aspects of Wyness's (2011) analysis, they found that the higher achievement levels at Key Stage 4 in London and these other cities could mostly be explained by prior attainment at Key Stage 2:

This suggests that the big improvement over the last decade in FSM results in London and other big cities is unlikely to have been driven by secondary schools, as was previously thought. Instead, the roots are likely to lie in primary schools. (Greaves et al., 2014: 7)

Burgess (2014: 2) also analysed GCSE data between 2004 and 2013. His analysis suggested that the ethnic composition of its students - fewer White British pupils, 
the lowest-performing group, and more high-performing pupils - played an important part and he concluded provocatively with the claim that 'the basis for [London's] success lies more with pupils and parents than it does with policy-makers' (Burgess, 2014: 16). Blanden et al. (2015) also focused on the improvements for disadvantaged pupils, looking at Key Stage 2 and Key Stage 4 performance. They found that the performance of disadvantaged pupils had improved substantially from as early as the mid-1990s, thus predating the London Challenge and initiatives often associated with London's gains, such as the initial academies programme. Disadvantaged pupils were four percentage points less likely to achieve the standard benchmark at age 16 than in other parts of England in 1995. By 2003 they were five percentage points more likely to achieve this and by 2013, 19 percentage points more likely. They also echoed Burgess (2014) in suggesting that London's higher performance levels might be explained in part by the fact that disadvantaged pupils in London were much less likely to have a White British background than in other parts of England. Finally, they reiterated Greaves et al. (2014) in emphasizing that improvements also occurred in primary schools, suggesting further that focusing predominantly on secondary interventions is misleading. Further discussion was prompted by Sir Michael Wilshaw's identification of a 'North-South divide' between schools in England in his final two annual inspection reports (Ofsted, 2015, 2016), in which London appeared to be largely responsible for the difference in performance between these loosely defined areas.

Given all this uncertainty about the nature and size of the London effect and the acknowledged difficulties of both improving educational outcomes through areabased initiatives and identifying the contributing factors when they do improve (Batty, 2013; Kerr et al., 2014), this article largely restricts itself to a descriptive analysis of attainment data in attempting to answer a relatively straightforward research question: did London's state-funded schools continue to outperform the rest of England at Key Stages 2 and 4 in 2016, following significant changes to both assessment frameworks and performance measures?

\section{Context: Increasing fragmentation and change overload}

In a study of school and system leadership in England a decade ago, Huber et al. (2008: 142) highlighted the 'overload and extreme fragmentation characteristic of complex social systems including education'. If anything, this has intensified in the intervening period. This section outlines the fragmentation of the middle tier between schools and government and the initiative overload in terms of curriculum and assessment change which schools have faced since the coalition government was formed in 2010, as they represent the context in which London schools were attempting to sustain the improvements made in the preceding period.

\section{Fragmentation}

The fragmentation of the school system can in part be traced back to the creation of academies, initially launched by the Labour government in 2000 . The first three academies opened in 2002 and by the general election of 2010 the number had risen to 203. The coalition government elected that year put the expansion of the academies programme at the centre of its ambition to create a 'self-improving system' (Hargreaves, 2010). By January 2018 there were 6,996 academies in England and 64.7 per cent of secondary schools had become academies.

In England academies are publicly funded schools that operate independently of local authorities within a framework designed to promote innovation, raise school 
standards and increase levels of achievement for all children. They have greater autonomy than traditional state schools in areas such as delivery of the curriculum, setting of staff pay and conditions and changing the length of school terms and school days. There are two types of academies: sponsored academies and converter academies. Until 2010, all academies were sponsored academies, created to replace schools regarded as underperforming with the aim of improving educational standards and raising the aspirations of pupils from all backgrounds, including the most disadvantaged. Converter academies are successful schools that chose to convert to academies in order to benefit from the increased autonomy academy status brings. They were introduced in 2010 as part of the coalition government's plan to broaden the academy programme and enable all schools to become academies. Alongside this, a second major policy priority at the Department for Education (DfE) from May 2010 was the creation of free schools, a specific type of academy set up and run independently of local authorities, based on proposals by groups of educators, parents, charities and others. The creation of free schools, as well as university technical colleges (UTCs) and studio schools has further increased the fragmentation within the English schooling system. As Glatter emphasized, these developments have precedents:

There were attempts in the 1990s by the Conservative government to create independent state schools - the so-called grant-maintained schools and City Technology Colleges - which were free of local authority control. The new system is often seen as simply a reincarnation of those failed projects. (2014: online)

One of the defining features of the creation and growth of these new school types is that they were deliberately taken out of local authority control (O'Shaughnessy, 2012). More importantly, the increase in the proportion of schools, particularly secondaries, outside the control of local authorities since 2010 has been unprecedented. It has been accompanied by policy changes such as the discontinuation of local authority and school-level target setting and the large-scale downsizing of local authority school improvement teams, even though, as Hayes and Cassen (2014: 26) found, these teams played a key role 'in raising standards and in holding schools to account for the performance of their pupils' in London schools between 2003 and 2013. In 2015, the House of Commons Education Committee's report on academies and free schools concluded that there had been too much speed and too little transparency in developing the academies programme (HoCEC, 2015: 4): We recommend that the DfE review the lessons of the wholesale conversion of the secondary sector to inform any future expansion.' The Committee also made the crucial point that there was no evidence for the superiority of either free schools or academies over local authority schools. Some of the tension that persists in the English school system results from what Lubienski (2014) has termed the 'disintermediation' through which local authorities the intermediate structures between national government and schools - have seen their power and role diminished since 2010. This has been heightened by the fact that 'as LAs' influence and authority has declined, other intermediary forms, such as academy chains and teaching school alliances, have only gradually emerged to take on some of their responsibilities' (Jopling and Hadfield, 2015: 53).

In the course of the Education Committee's inquiry, they made several recommendations in relation to the middle tier of which O'Shaughnessy (2012) was so critical, including expanding the numbers of regional school commissioners, redefining the role of local authorities and clarifying how these two middle tier functions interrelate. The Committee suggested local authorities' responsibilities 'should include the 
championing of the interests of local children, families and employers in ensuring high quality, accessible local provision, rather than championing the schools themselves' (HoCEC, 2015: 67). Hatcher (2014: 369) went further, criticizing the imprecision of the term 'championing', also assigned to local authorities in the coalition government's White Paper, The Importance of Teaching (DfE, 2010), and suggesting that the new forms of middle tier partnerships in which local authorities have become increasingly involved since 2010 have rendered them 'relatively powerless and the pressure on them to conform to government agendas is intense'.

\section{Initiative overload}

References to initiative overload and the negative consequences of excessive change in education have become ubiquitous. Tomlinson (2005: 90) described the incoming Labour government of 1997 as continuing 'the avalanche of education-related policy initiatives, legislation and advice [that] had characterized 18 years of Conservative rule' and, if anything, the pace of change and intervention has increased since. Initiative overload was cited second only to workload as a factor in teacher retention in a General Teaching Council for England (GTCE) survey of teachers undertaken in 2003 (Smithers and Robinson, 2003) and has been associated with the British political system's tendency towards high levels of public sector intervention (Gibton, 2013; Glatter, 2017). For our purposes, it is sufficient to briefly outline the changes that were made to curriculum and assessment at Key Stages 2 and 4, as these are the assessment points on which our analysis focuses.

At GCSE, major changes were introduced from September 2015 in English and mathematics, with other subjects being revised subsequently. The key changes included the move to 'new, more demanding content', assessment mainly by examination at the end of two years of study and a new grading scale of 9 to 1 . However, the changes that had the most impact were the decisions made by the DfE, following the Wolf Report's (2011) review of vocational education, to reduce the range of qualifications that could be included in school performance tables and to introduce a 'first-entry' rule, which was phased in for the 2014 examinations (DfE, 2013).

The first of these changes meant that the number of non-GCSEs that could be included in the 2013/14 performance tables was reduced to two and no qualification could be counted as equivalent to more than one GCSE. Prior to this change, some qualifications, such as Business and Technology Education Council diplomas (BTECs), equated to up to four GCSEs. The introduction of subject discounting meant that multiple entries in the same subject, but in different types of qualification, could no longer be included in performance tables, with only one qualification being counted.

The first-entry rule was phased in for the 2014 Key Stage 4 performance tables and it only applied to examinations taken from September 2013. As a result, in the 2014 performance tables, a student's best result from qualifications entered prior to September 2013 was still counted if it was better than their first result from the 2013/14 academic year. The aim of the first-entry rule was to reduce early and repeated examination entries in the same subject, which had been possible under previous best-entry rules. The impact of both rule changes resulted in a reduction in national performance in the percentage of pupils achieving $5+$ GCSE grades at $A^{*}-C$ including English and mathematics in 2014.

At primary level, the tests pupils took at the end of Key Stages 1 and 2 which gave them a National Curriculum level in reading, writing and mathematics were used to measure the school's achievement and the pupils' progress before September 2014. 
Children were expected to achieve at least Level 4 in reading and writing at the end of Key Stage 2. From 2014, these levels were discontinued and schools were allowed 'the freedom to decide how to teach their curriculum and how to track the progress that pupils make' (DfE, 2014). In September 2015, a new primary curriculum was introduced, described as a 'more challenging national curriculum' which 'set high expectations so that all children can reach their potential and are well prepared for secondary school' (DfE, 2014: 4-5). Like the changes at Key Stage 4, it was criticized on a number of grounds, not least for being reductionist in its focus on core subjects, naive in its use of international comparisons and traditionalist in its retention of a two-tier curriculum (Alexander, 2012). In addition, from 2016, the tests to be taken by children at the end of Key Stages 1 and 2 were changed to make them more challenging. At Key Stage 2 they were marked externally, with separate teacher assessments given to parents in the core subjects. All of these alterations mean that the pace of change, already considered to be drastic, increased further from 2014. This prompted our interest in examining whether the London effect survived these changes.

\section{Methodology}

The methodological approach adopted in this research has been a quantitative analysis of educational attainment data taken from statistical first releases (SFRs) from the Department for Education. The analysis includes data at the national level for England, regional data at the level of government regional office and local authority level data. The analysis focuses on educational outcomes at Key Stage 2 and Key Stage 4 and includes trend data to highlight when performance in London started to outstrip national data and single year data for 2016 to assess whether London was still outperforming national and other regions in 2016, as it had up to 2015.

\section{An overview of educational performance in London to 2015}

This section provides a brief overview of educational performance in London up to 2015, focusing on Key Stages 2 and 4. It highlights when performance in London began to outstrip the national average and where it had reached by 2015. The performance graphs in this section extend the analysis in Hayes and Cassen (2014) and the studies discussed above in relation to the London effect.

\section{Key Stage 2}

Performance at Key Stage 2 improved steadily year on year from 2005 to 2015 both in London and nationally, with only a slight national drop in 2009. Figure 1 illustrates this in terms of the percentage of children achieving Level 4+ in English and mathematics combined from 2005 to 2012 and Level 4+ in reading, writing and mathematics combined from 2013 to 2015 , comparing London with the national average. It should be noted that since 2013 it has not been possible to calculate an overall level in English as from this point onwards the outturn for English were reported separately as the Reading Test Level and the Writing Teacher Assessment Level. The measure used from 2013 therefore is the percentage achieving Level 4+ in reading, writing and mathematics combined. Figure 1 shows London first outperforming national at Key Stage 2 in 2009 and then moving further ahead of national year on year up to 2015. In 2009 performance in London was one percentage point above the national level, rising to two points above in 2012 and four above in 2015. 


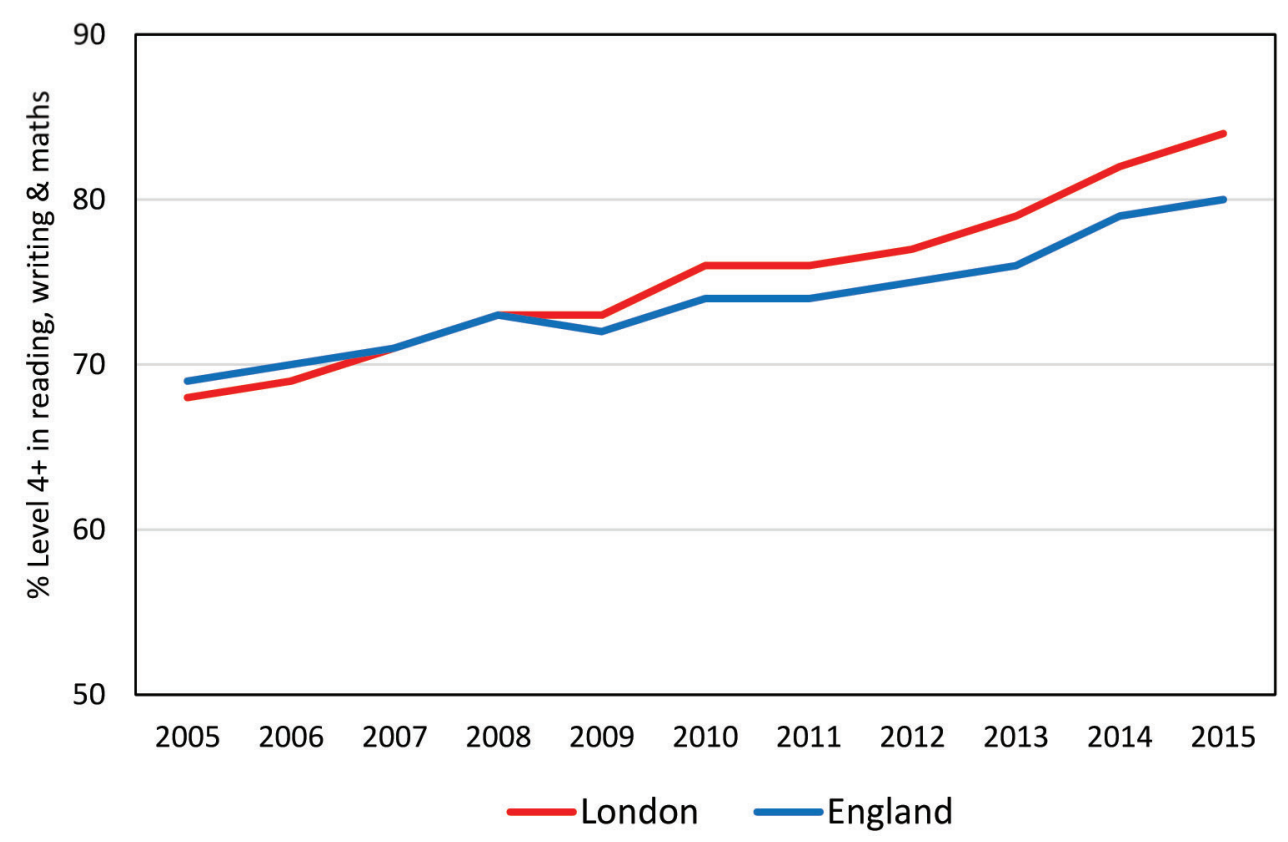

Figure 1: Key Stage 2, percentage Level 4+ in reading, writing and mathematics combined, 2005-15: London and national (DfE statistical first releases (SFRs), 2005 to 2015)

\section{Key Stage 4}

Performance at Key Stage 4 improved steadily year on year from 1998 to 2013 both in London and nationally. Figure 2 shows the performance in terms of the percentage of students achieving 5+ GCSE grades at $A^{*}-C$ including English and mathematics from 1998 to 2016. It shows London first outperforming national at Key Stage 4 in 2004 and then moving further ahead of the national average year on year up to 2013. There were decreases in performance in London and nationally between 2014 and 2016. However, performance in London remained higher than national, despite the changes, outlined above, made by the DfE to the calculation of the performance measure from 2013.

Although Parameshwaran and Thomson (2015) suggested that the changes made may have had a significant negative impact on pupils' access to subjects and qualifications, Figure 2 indicates that results improved slightly nationally in 2015. However, in 2015 Key Stage 4 results in London dropped for the second year in a row, and London and the national level both dropped fractionally in 2016. The net impact of this led to a slight narrowing of the gap between London and national, which suggests that the negative impact of the rule changes was greater in London than it was nationally, although London still outperformed the rest of the country. In 2004 performance in London was 0.7 percentage points above national, rising to 4.7 points above by 2014 and 3.6 points above in 2015. In 2016, the first year after this measure was effectively discontinued, London was 2.7 percentage points above national.

Figure 3 focuses on the performance of individual local authorities in London. It illustrates their performance in terms of the percentage of students achieving 5+ GCSE grades at $A^{*}-C$ including English and mathematics at four points in time: 1998, 2003, 2008 and 2013, against the national performance at the same point in time. In 1998, 28 out of 32 London local authorities were below national on this measure. The number dropped to 21 in 2003 and 16 in 2008. However, the most dramatic improvement occurred between 2008 and 2013, when the number of London local authorities 


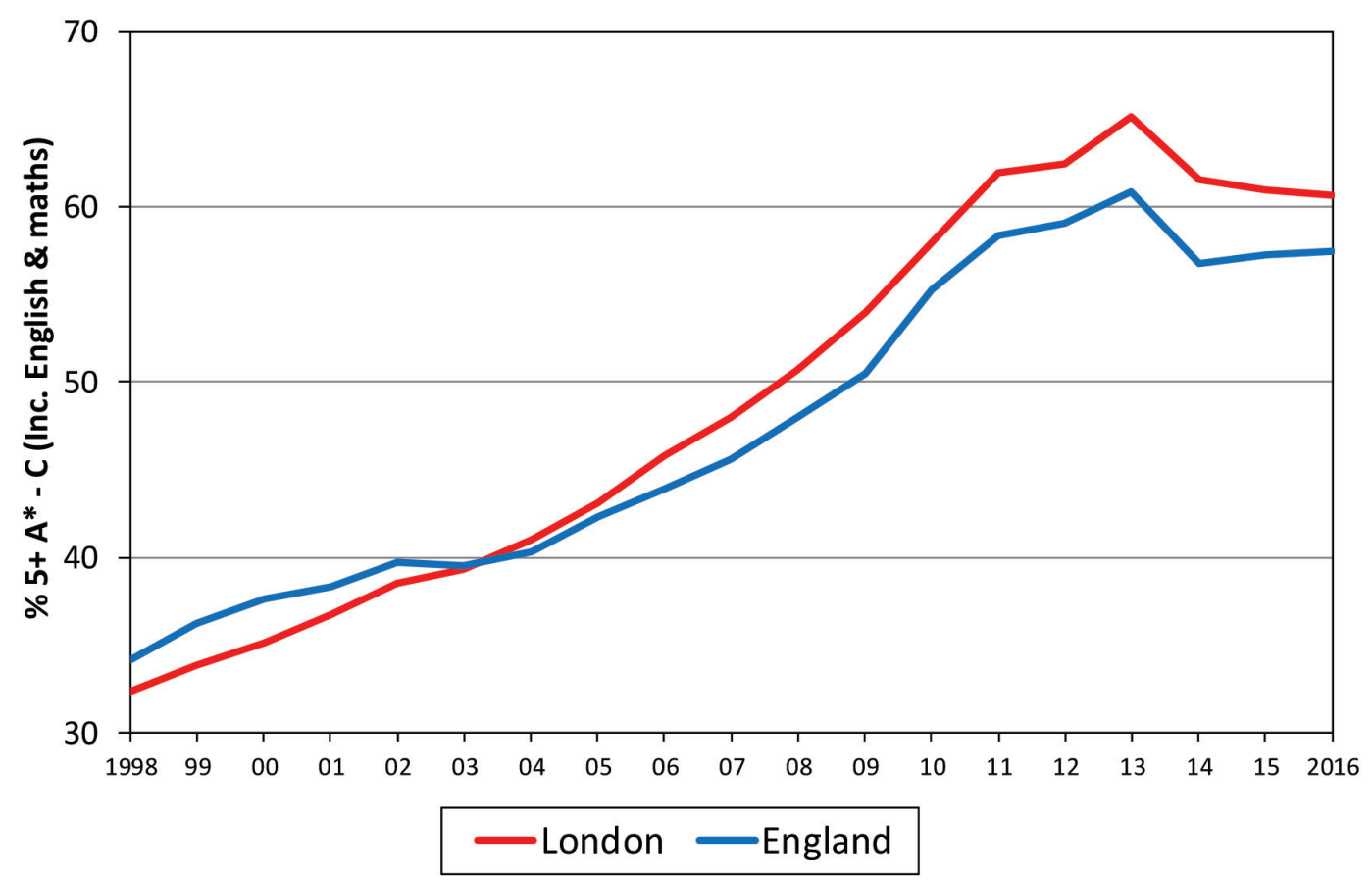

Figure 2: Key Stage 4, percentage 5+ $A^{*}-C$ including English and mathematics, 1998-2016: London and national (DfE Key Stage 4 school performance tables, 1998 to 2016 )

below the national average dropped to only six. Between 1998 and 2013, national performance on this measure improved by 23.8 percentage points. Over the same period, 31 out of 32 London local authorities improved by more than 23.8 percentage points, with nine of them improving by more than 40 percentage points.

The six local authorities with the lowest results in 1998 - Islington, Hackney, Tower Hamlets, Southwark, Lambeth and Haringey - which were therefore those with the greatest distance to travel to reach the national average, were among those who made the greatest improvements between 1998 and 2013. By 2013, all six of them were above the national average for the percentage of students achieving 5+ GCSE grades at $A^{*}-C$ including English and mathematics. Against a national performance of 60.8 per cent in 2013, Hackney had reached 61.2 per cent, Islington had reached 63.5 per cent and Tower Hamlets had reached 64.7 per cent.

\section{Extending the analysis: Educational performance in London in 2016}

This section considers the impact of the significant changes made to assessment and the curriculum in 2016 at Key Stages 2 and 4, as well as the ongoing fragmentation associated with increased academization. As already emphasized, the analysis focuses on 2016 because its results were the first to reflect the changes to the assessment frameworks and performance measures at both Key Stages 2 and 4 . This also means that the results are not directly comparable to previous years.

\section{Key Stage 2}

The first year in which 'reaching the expected standard or above' was the measure used at Key Stages 1 and 2 was 2016. Figure 4 shows the Key Stage 2 results in this year for the percentage of pupils reaching the expected standard or above in the 


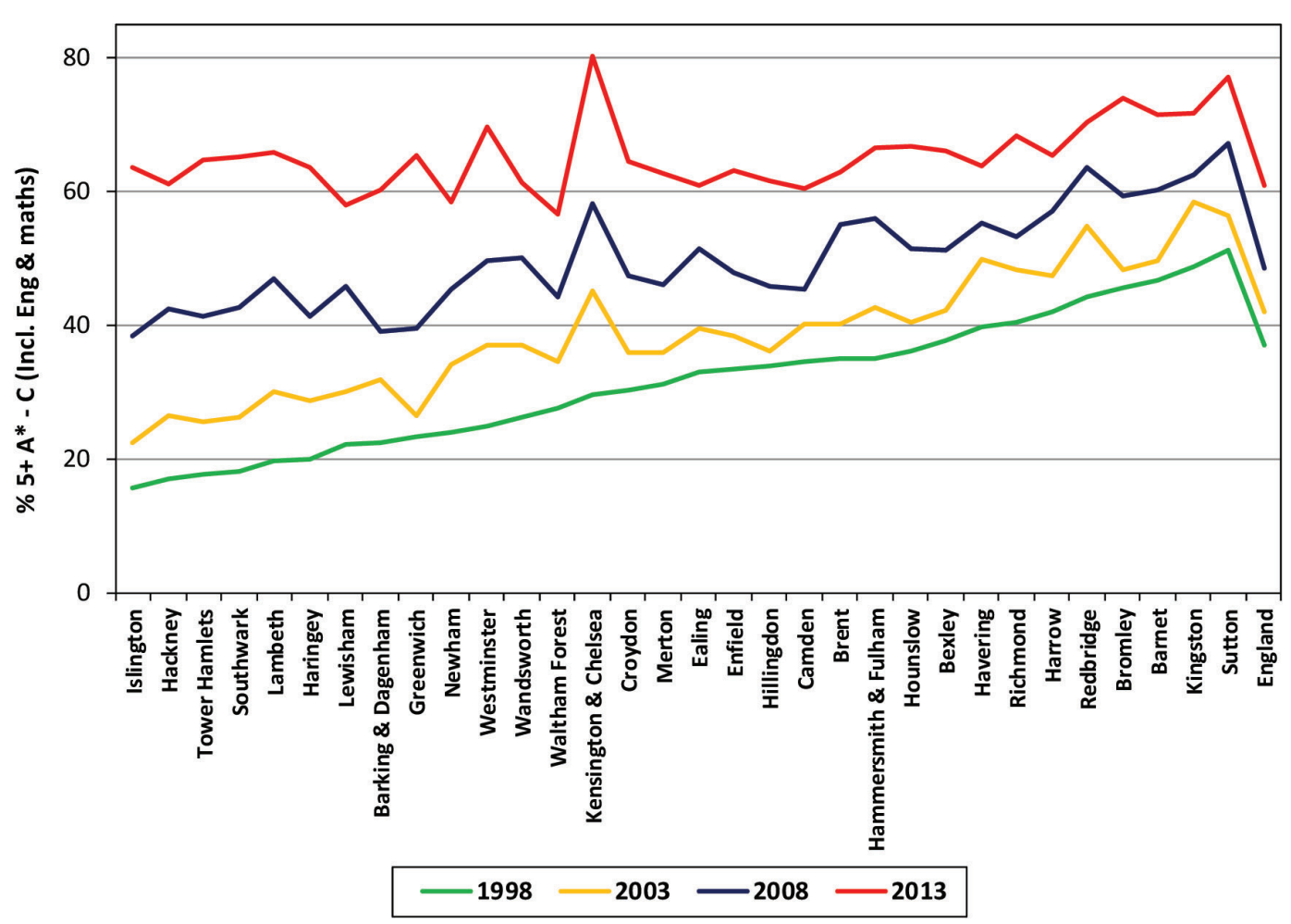

Figure 3: London LAs GCSE performance versus England, percentage 5+ $A^{*}-C$ including English and mathematics in 1998, 2003, 2008 and 2013

combined measure of reading, writing and mathematics by English region. It indicates that pupils in Inner and Outer London outperformed all other English regions in all three subjects. Performance in London was also better than national performance in the three subjects combined. On the basis of these outturns being reported for the first time in 2016 under the new assessment framework, London continued to outperform the rest of England at Key Stage 2. Given Wilshaw's comments in his annual report that year about the enduring 'North-South divide' (Ofsted, 2016), it is noteworthy that schools in the North East were closest in performance to those in London.

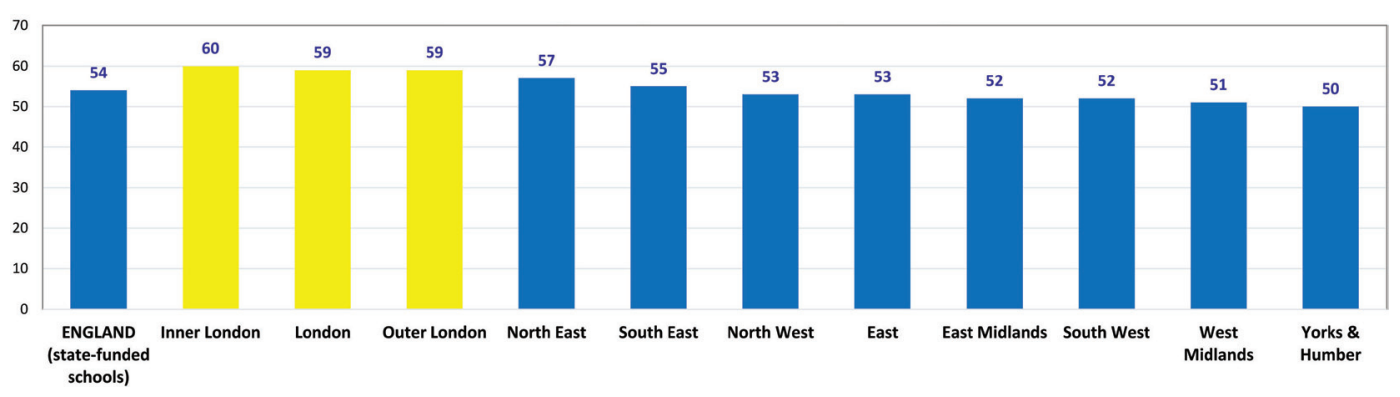

Figure 4: Percentage of pupils reaching the expected standard at Key Stage 2 in 2016 in reading, writing and mathematics (combined) by English region

As well as threshold measures of attainment, it is also possible to analyse the outcomes of the new progress measures at Key Stage 2. Figure 5 shows the Key Stage 2 progress scores in the reading test by English region in 2016. The progress scores are reported in relation to a national score of zero. A score of zero means that an individual pupil 
has made progress in line with what would be expected nationally for pupils with similar prior attainment from Key Stage 1. Positive scores indicate that more progress than expected was made, while negative scores mean less progress than expected was made.

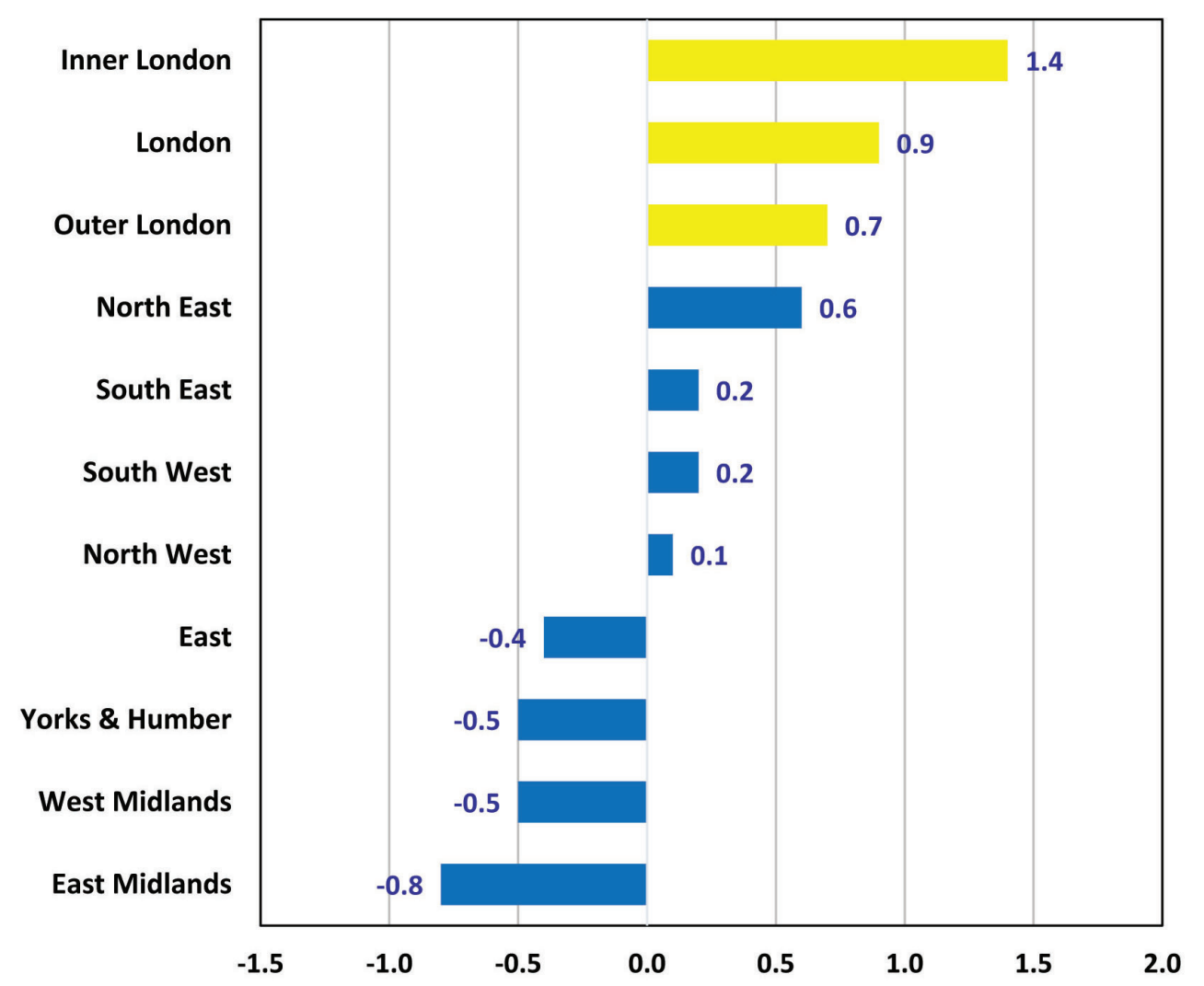

Figure 5: Key Stage 2 progress scores in reading by English region in 2016

Figure 5 indicates that Inner and Outer London had the highest positive progress scores of all English regions, with the North East close behind and considerably ahead of the other regions. Although not illustrated here, the same pattern was shown in the writing and mathematics progress scores, with London pre-eminent in all three subjects and the North East again the next highest performing region in these subjects.

As the Key Stage 2 assessments in 2016 were the first to assess the new, more challenging national curriculum and the new 'achieving the expected standard or above' measure, the performance outturns for 2016 are not directly comparable to those for earlier years. However, the new Key Stage 2 assessments were deemed to be more difficult than their predecessors. BBC News (2016) reported that 'almost half of primary pupils in England have failed to meet a new tough standard in reading, writing and mathematics'.

\section{Key Stage 4}

In 2016, the old Key Stage 4 headline measure (the percentage of students achieving 5+ GCSE grades at $A^{*}-C$ including English and mathematics) was effectively discontinued by the DfE and two new measures were introduced: Attainment 8 and Progress 8 . Attainment 8 measures the achievement of a student across eight qualifications including mathematics (double-weighted) and English (double-weighted), three 
further qualifications that count in the English Baccalaureate (EBacc) measure, and three further qualifications that can be GCSE qualifications (including EBacc subjects) or any other non-GCSE qualifications on the DfE-approved list. Each individual grade a student achieves is assigned a point score, which are then added together to give a student's Attainment 8 score. English and mathematics point scores are doubleweighted to signify their importance. Progress 8 is a value-added measure that takes students' Attainment 8 scores and adjusts them for their prior attainment from Key Stage 2. Like Key Stage 2 progress scores, the Progress 8 scores are reported around a national score of zero, with a score of zero meaning that an individual student has made progress in line with what would be expected for students nationally with similar prior attainment from Key Stage 2. Positive scores indicate that more progress than expected has been made, while negative scores mean less progress than expected has been made (DfE, 2017). While the introduction of Progress 8 and the inclusion of a progress measure in minimum floor standards for the first time has been welcomed by some, concerns have been raised about its fairness when used to assess schools with large numbers of disadvantaged students (Andrews, 2017).

Figure 6 illustrates the average Attainment 8 scores by English region in 2016. The outturns show that Inner and Outer London had higher Attainment 8 scores than all other regions and that performance in London was better than it was nationally.

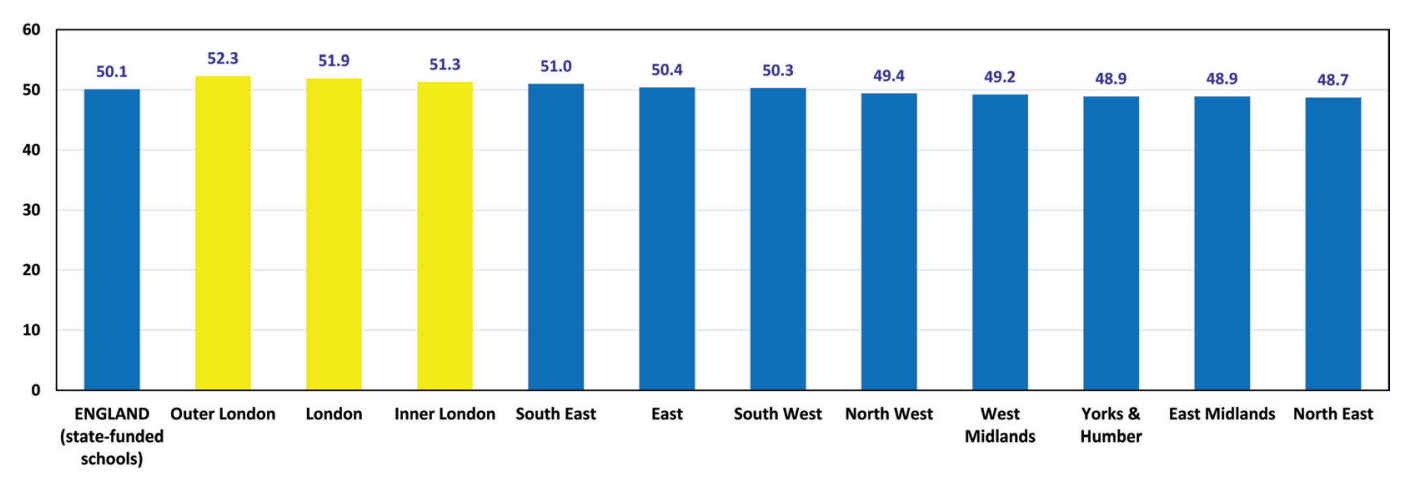

Figure 6: Average Attainment 8 score by region at Key Stage 4 in 2016

Figure 7 shows the average Progress 8 scores by English region in 2016. The outturns show that Inner and Outer London had higher Progress 8 scores than all other regions and therefore, on average, students in London made more progress than similar pupils nationally. The London Progress 8 score of +0.16 means that students in London achieved around a sixth of a grade higher in each GCSE subject compared to students with similar prior attainment nationally. It also suggests that London schools' capacity to address disadvantage has survived recent changes. It is less clear why secondary schools in the North West and the North East in particular performed so much less well than primaries in these regions. This needs to be explored in future research.

In summary, the 2016 educational outcomes at Key Stages 1, 2 and 4 show that performance in London remains pre-eminent compared to national performance and to performance in all of the other English regions, even following the changes that were introduced to the assessment frameworks and educational accountability measures. Performance at Key Stages 2 and 4 was also better in London than the national level in terms of both attainment and progress. 


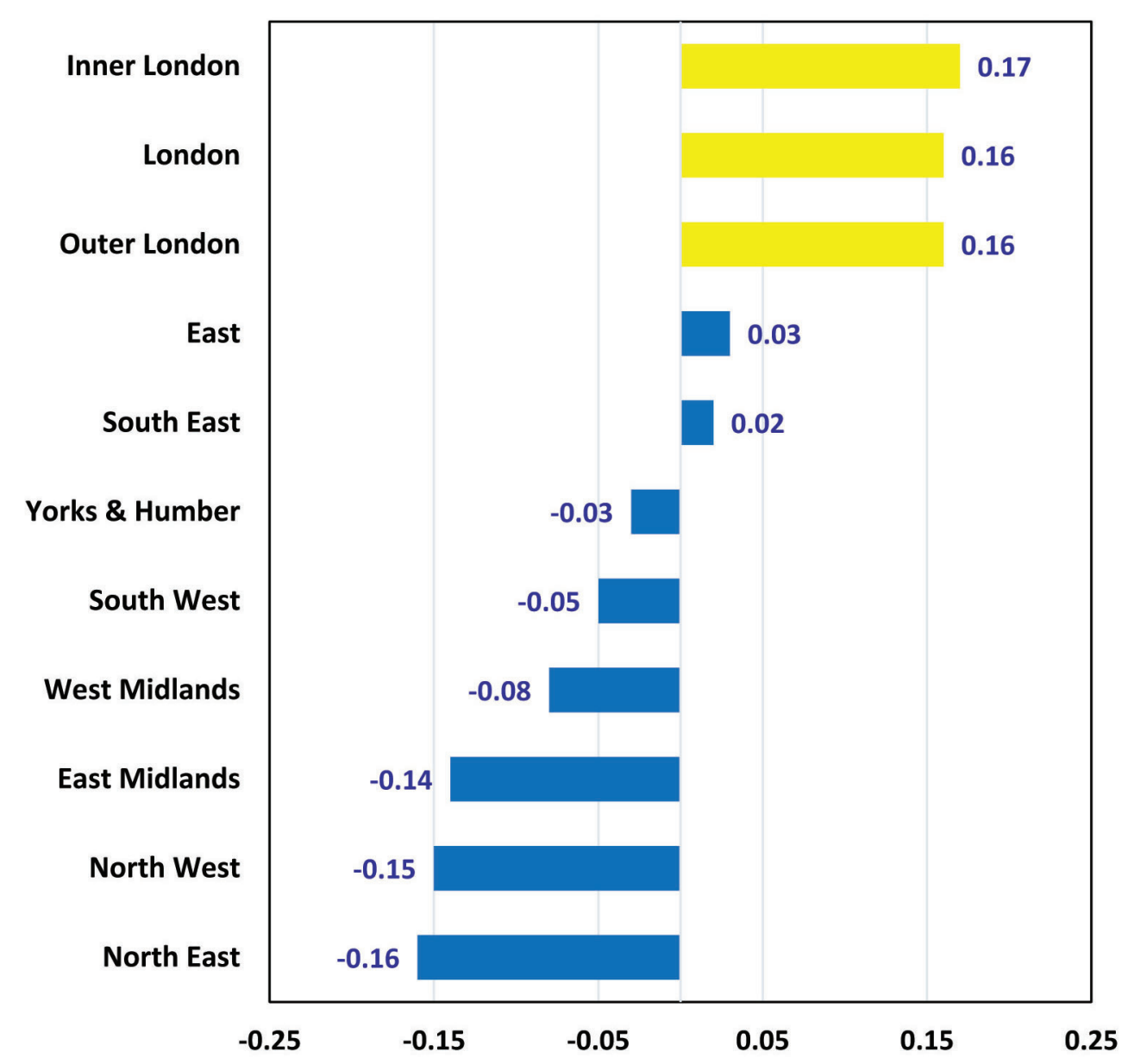

Figure 7: Average Progress 8 scores by English region at Key Stage 4 in 2016

\section{Conclusions}

This article has set out to take stock and answer a relatively straightforward question at a key historical point in school reform: did London's state-funded schools continue to outperform the rest of England at Key Stages 2 and 4 in 2016, following significant changes to both assessment frameworks and performance measures? The 2016 educational outcomes at Key Stages 2 and 4 show that performance in London remains pre-eminent compared to national performance and to performance in all other English regions, even following the changes to the assessment frameworks and to the measures of educational accountability that were first introduced in 2014. Performance at Key Stages 2 and 4 was also better in London than nationally in terms of both attainment and progress. The fact that schools elsewhere recovered a little more quickly from the initial redefinition of the floor standard measure in 2015 than schools in London at Key Stage 4 (see Figure 2) may suggest that London's schools were more effective at 'gaming' the system by including greater numbers of nonGCSEs in performance tables than other regions. However, the 2016 Attainment 8 and Progress 8 data, which show London outperforming all other regions, indicate that the schools seem to have recovered their position subsequently.

The educational performance data for 2017 at Key Stage 2 were published by the Department in December 2017 and the Key Stage 4 data were published in 
January 2018. This shows that the high standards in London were sustained. At Key Stage 2, London outperformed all other English regions for the percentage of pupils achieving the expected standard in all subjects and likewise in terms of progress in reading, writing and mathematics. The pattern was the same at Key Stage 4, where London outperformed all other regions for Attainment 8, Progress 8 and the English Baccalaureate.

Given that London seems to have retained its pre-eminence through the recent upheavals in both the primary and secondary phases, more research needs to be undertaken in both to attempt to identify how these gains were made and whether they can be transferred to other parts of the country. This also applies to regions such as the North East, where primary schools have consistently outperformed other regions outside London in recent years. It is also important to examine whether patterns of disadvantage or ethnic composition continue to have differential effects in London, which we did not have space to examine in this article. However, London schools' performance when compared internationally might not be as impressive as it is nationally. Further research is also needed to extend comparative work by Jerrim and colleagues (Jerrim and Wyness, 2016; Jerrim et al., 2017), which has attempted to benchmark London against other major cities using Programme for International Student Assessment (PISA) and Trends in International Mathematics and Science Study (TIMSS) data, and Cajic-Seigneur and Hodgson's (2016) identification of the persistently high levels of young people not in education, employment or training in some parts of London.

The article has also reflected on the impact on educational outcomes of the fragmentation occurring within the English education system, as evidenced over the last two decades by the creation of a multiplicity of new school types no longer accountable to their local authority. These have included sponsored academies, converter academies, free schools, university technical colleges and studio schools. Since the inception of academies in 2000, and much more intensely since 2010, the increasing fragmentation of the school system in England has resulted in a diminished role for local authorities in being able to hold schools in their area to account and work with them to drive up standards (Hatcher, 2014; Simkins et al., 2015). However, the consistently better average performance when compared to the rest of England of schools in London, where many local authorities still work in collaboration with their schools, suggests that local authorities have a positive effect, regardless of the type of schools in their area and how fragmented that mix of schools might be. This model of local authorities and schools working in partnership, while by no means unique to London, may be part of the reason why London's schools remain pre-eminent in terms of educational outcomes compared to the rest of the country.

The fragmentation of the system and the more rapid shift in the secondary phase to schools becoming academies has led to a mixed picture of educational outcomes by school type, with convertor academies performing better than local authority maintained schools, but with sponsored academies performing worse (Hayes and Gul, 2017). The picture in the primary phase, where academization has been less popular, is different. National Key Stage 2 data for the percentage of pupils who achieved the expected standard or above in reading, writing and mathematics combined indicate that 80 per cent of the successful pupils were in local authority schools, 15 per cent in converter academies, 5 per cent in sponsored academies and fewer than 1 per cent in free schools. This appears to confirm the Education Select Committee's finding that academy status has not had a significant impact on attainment in primary schools. This 
may have been one of the factors which contributed to the gradual removal of the government's push for all primary schools to convert to academy status after 2015.

The pre-eminence of London has been sustained, regardless of the changes to assessment frameworks and the new measures of educational success that have been introduced nationally since 2014. Even though local authority input to London's educational success might vary between local authorities, support for school improvement has continued in many of them. Therefore, the conclusion is that the sustained success of London's schools provides greater evidence of continuous improvement than mere fragile gains. Although the English education system is probably more fragmented than at any time in the past 30 years, London schools' continuing success might be regarded as evidence that we should heed the National Association of Head Teachers' (NAHT) warning in its submission to the Education Select Committee 'against seeing structural reforms as a panacea for school improvement' (HoCEC, 2015: 21). Furthermore, the apparent simplicity of managing schools from the centre is not an effective or sustainable replacement for a middle tier of local system leadership delivered through local authorities.

\section{Notes on the contributors}

Sean Hayes is Head of Children's Services Performance and Data in Hounslow Council. Currently British Education Research Association (BERA) Treasurer, he is an Honorary Norham Fellow at the Education Department of the University of Oxford. He is also a governor at a secondary school in London and his research interests relate to educational attainment and the intersection of social class, race and gender.

Michael Jopling is Professor of Education and Director of the Education Observatory at the University of Wolverhampton. He has been involved in research in all areas of education, but his research interests centre on working with schools on areas such as school and multi-agency collaboration, education policy, educational leadership and engaging teachers and practitioners in participatory research and action enquiry.

Ruki Gul is an experienced education analyst and researcher who has worked in the Children's Services Performance and Data Team in Hounslow Council for over 10 years and is a member of the London Education Research Network. Her research interests include the provision of high-quality performance data analysis for schools.

\section{References}

Alexander, R. (2012) 'Neither national nor a curriculum?'. Forum, 54 (3), 369-84.

Andrews, J. (2017) 'Analysis: The introduction of Progress 8'. Online. https://epi.org.uk/wp-content/ uploads/2017/03/The_Introduction_of_P8.pdf (accessed 8 March 2018).

Baars, S., Bernardes, E., Elwick, A., Malortie, A., McAleavy, T., Mclnerney, L., Menzies, L. and Riggall, A. (2014) Lessons from London Schools: Investigating the success. Reading: CfBT Education Trust.

Batty, E. (2013) 'Addressing educational disadvantage in deprived communities: Evidence from the New Deal for Communities Programme in England'. Urban Studies, 50 (8), 1523-39.

BBC News (2016) 'Almost half of primary pupils miss new Sats standard'. BBC News, 5 July. Online. www.bbc.co.uk/news/education-36712029 (accessed 8 March 2018).

Blanden, J., Greaves, E., Gregg, P., Macmillan, L. and Sibieta, L. (2015) Understanding the Improved Performance of Disadvantaged Pupils in London (Social Policy in a Cold Climate Working Paper 21). London: Centre for Analysis of Social Exclusion. Online. http://sticerd.Ise.ac.uk/dps/case/ spcc/wp21.pdf (accessed 8 March 2018).

Burgess, S. (2014) Understanding the Success of London's Schools (Working Paper 14/333). Bristol: Centre for Market and Public Organisation. 
Cajic-Seigneur, M. and Hodgson, A. (2016) 'Alternative educational provision in an area of deprivation in London'. London Review of Education, 14 (2), 25-37.

Cook, C. (2013) 'London schoolchildren perform the best'. The Financial Times, 13 January.

DfE (Department for Education) (2010) The Importance of Teaching. London: Department for Education

DfE (Department for Education) (2013) Reforming the Accountability System for Secondary Schools: Government response to the February to May 2013 consultation on secondary school accountability. London: Department for Education.

DfE (Department for Education) (2014) Reforming Assessment and Accountability for Primary Schools: Government response to consultation on primary school assessment and accountability. London: Department for Education.

DfE (Department for Education) (2017) Secondary Accountability Measures: Guide for maintained secondary schools, academies and free schools. London: Department for Education.

Gibton, D. (2013) Law, Education, Politics, Fairness: England's extreme legislation for education reform. London: Institute of Education Press.

Glatter, R. (2014) 'The academies model: Fragmentation, favouritism and failure'. The Guardian, 7 January. Online. www.theguardian.com/teacher-network/teacher-blog/2014/jan/07/academiesfree-schools-system-phased-out (accessed 8 March 2018).

Glatter, R. (2017) '“Because we can": Pluralism and structural reform in education'. London Review of Education, 15 (1), 115-25.

Greaves, E., Macmillan, L. and Sibieta, L. (2014) Lessons from London Schools for Attainment Gaps and Social Mobility. London: Social Mobility and Child Poverty Commission.

Hargreaves, D.H. (2010) Creating a Self-Improving School System. Nottingham: National College for Leadership of Schools and Children's Services.

Hatcher, R. (2014) 'Local authorities and the school system: The new authority-wide partnerships'. Educational Management Administration and Leadership, 42 (3), 355-71.

Hayes, S. and Cassen, R. (2014) 'The transformational shift in educational outcomes in London 2003 to 2013: The contribution of local authorities'. Paper presented at the British Educational Research Association (BERA) Annual Conference, Institute of Education, London, 23-25 September 2014.

Hayes, S. and Gul, R. (2017) 'The effect of changing assessment frameworks on London's educational success: Continuous improvement or fragile gains?'. Paper presented at the British Educational Research Association (BERA) Annual Conference, University of Sussex, Brighton, 5-7 September 2017.

House of Commons Education Committee (HoCEC) (2015) Academies and Free Schools: Fourth report of session 2014-15. London: Stationery Office.

Huber, S., Moorman, H. and Pont, B. (2008) 'The English approach to system leadership'. In Pont, B., Nusche, D. and Hopkins, D. (eds) Improving School Leadership: Volume 2: Case studies on system leadership. Paris: OECD Publishing, 111-52.

Hutchings, M., Greenwood. C., Hollingworth, S., Mansaray, A., Rose, A., Minty, S. and Glass, K. (2012) Evaluation of the City Challenge Programme (Research Report DFE-RR215). London: Department for Education.

Jerrim, J. and Wyness, G. (2016) 'Benchmarking London in the PISA rankings'. London Review of Education, 14 (2), 38-65.

Jerrim, J., Perera, N. and Sellen, P. (2017) English Education: World class in primary? London: Education Policy Institute.

Jopling, M. and Hadfield, M. (2015) 'From fragmentation to multiplexity: Decentralisation, localism and support for school collaboration in England and Wales'. Journal for Educational Research Online, 7 (1), 49-67.

Kerr, K., Dyson, A. and Raffo, C. (2014) Education, Disadvantage and Place: Making the local matter. Bristol: Policy Press.

Kidson, M. and Norris, E. (2014) Implementing the London Challenge. London: Joseph Rowntree Foundation/Institute for Government.

Lubienski, C. (2014) 'Re-making the middle: Dis-intermediation in international context'. Educational Management Administration and Leadership, 42 (3), 423-40.

Mujtaba, T. (2016) 'Education in London: Challenges and opportunities for young people'. London Review of Education, 14 (2), 1-3.

Ofsted (2015) The Annual Report of Her Majesty's Chief Inspector of Education, Children's Services and Skills 2014/15. London: Ofsted. 
Ofsted (2016) The Annual Report of Her Majesty's Chief Inspector of Education, Children's Services and Skills 2015/16. London: Ofsted.

O'Shaughnessy, J. (2012) Competition Meets Collaboration: Helping school chains address England's long tail of educational failure. London: Policy Exchange.

Parameshwaran, M. and Thomson, D. (2015) 'The impact of accountability reforms on the Key Stage 4 curriculum: How have changes to school and college Performance Tables affected pupil access to qualifications and subjects in secondary schools in England?'. London Review of Education, 13 (2), 157-73.

Simkins, T., Coldron, J., Crawford, M. and Jones, S. (2015) 'Emerging local schooling landscapes: The role of the local authority'. School Leadership and Management, 35 (1), 1-16.

Smithers, A. and Robinson, P. (2003) Factors Affecting Teachers' Decisions to Leave the Profession (Research Report RR430). Nottingham: Department for Education and Skills.

Tomlinson, S. (2005) Education in a Post-Welfare Society. Buckingham: Open University Press.

Wolf, A. (2011) Review of Vocational Education - The Wolf Report. London: Department for Education.

Woods, D., Husbands, C. and Brown, C. (2013) Transforming Education for All: The Tower Hamlets story. London: Tower Hamlets Council Communications Unit.

Wyness, G. (2011) London Schooling: Lessons from the capital. London: CentreForum. 